DOI: 10.20472/IAC.2018.044.050

\author{
BOB UTTL \\ Mount Royal University, Canada
}

STEPHANIE BELL

Mount Royal University, Canada

KATYA BANKS

Mount Royal University, Canada

\title{
STUDENT EVALUATION OF TEACHING (SET) RATINGS DEPEND ON THE CLASS SIZE: A SYSTEMATIC REVIEW
}

\begin{abstract}
:
Feldman (1984) reviewed studies investigating the relationship between SET ratings and the class size and concluded that their association was "very weak" and inverse. However, a detailed review of Feldman's meta-analysis reveals a number of serious methodological flaws that undermine his conclusion. Briefly, Feldman excluded studies that reported curvilinear relationships and did not consider a possibility that SET ratings may be the highest in smallest classes, decline sharply as the class size increases to 20 or 30 students and then level off; and that correlations reported in primary studies may be artifacts of calculating linear correlation coefficients over non-linear relationships. Accordingly, we conduct a new, up-to-date, comprehensive meta-analysis of the SET/Class size relationships using data from over 100 primary studies. The key results of our research show that (1) the primary studies frequently did not report necessary data to interpret their findings, and (2) the SET/Class size relationship is curvilinear, specifically, SET ratings are the highest in smallest classes, decline sharply as the class size increases to 20 to 30 students, and then level off revealing minimal SET/Class size relationship among studies with class sizes beyond 50 students.
\end{abstract}

\section{Keywords:}

student evaluation of teaching (SET), class size, validity 